\title{
Markers of inflammation and risk of coronary heart disease
}

\author{
Nadeem Sarwar ${ }^{\mathrm{a}, \mathrm{b}, *}$, Alexander J. Thompson ${ }^{\mathrm{b}}$ and Emanuele Di Angelantonio ${ }^{\mathrm{b}}$ \\ ${ }^{a}$ Section of Population Health, University of Aberdeen, UK \\ ${ }^{\mathrm{b}}$ Department of Public Health and Primary Care, University of Cambridge, UK
}

\begin{abstract}
Cardiovascular disease is the leading cause of global mortality, with coronary heart disease (CHD) its major manifestation. Although inflammation, the body's response to noxious stimuli, is implicated in several stages of CHD development, the relevance of circulating levels of markers of inflammation to CHD risk remains uncertain. This review summarizes available epidemiological evidence for four emerging inflammatory markers implicated in CHD (fibrinogen, C-reactive protein, lipoprotein-associated phospholipase $\mathrm{A}_{2}$ and interleukin-6); considers their likely utility in cardiovascular risk prediction; and outlines areas of outstanding uncertainty.
\end{abstract}

Keywords: inflammation, coronary, cardiovascular, prediction

\section{Introduction}

Cardiovascular disease is the leading cause of global mortality, accounting for almost one in every two adult deaths worldwide, with coronary heart disease (CHD) its major manifestation [1]. CHD results from atherosclerotic narrowing of the coronary arteries and the formation of an occlusive thrombus after plaque rupture [2]. The tendency for CHD to cluster in families (coefficient of familial clustering $[\lambda \mathrm{s}]$ estimated to be between 2 and 7) suggests that genetic variation importantly influences CHD risk [3]. On the other hand, studies of migrant populations indicate that CHD risk increases following movement from low-risk to highrisk regions (eg, Japanese in the USA) [4], suggesting that lifestyle and environmental factors also contribute importantly [5].

Inflammation, the body's response to noxious stimuli, is implicated in several stages of CHD development, including atherosclerosis, plaque destabilization, plaque rupture and post-ischaemia damage to the my-

* Corresponding author: Dr. Nadeem Sarwar, Section of Population Health, University of Aberdeen, Polworth Building, Foresterhill, Aberdeen, UK. E-mail: n.sarwar@abdn.ac.uk. ocardium [6,7]. Much uncertainty remains, however, about whether circulating levels of markers of inflammation are related to CHD risk. In particular, it remains unclear whether such markers are (i) causal in disease risk; (ii) correlates of conventional cardiovascular risk factors; (iii) markers of subclinical or prevalent disease; or some combination of these possibilities.

This review summarizes available epidemiological evidence for four emerging inflammatory markers implicated in CHD development; considers their likely utility in cardiovascular risk prediction; and outlines areas of outstanding uncertainty.

\section{Fibrinogen}

First isolated from horse plasma in 1876, fibrinogen is the most abundant clotting protein in circulation. A very large $(340 \mathrm{KDa})$ glycoprotein synthesized in the liver, fibrinogen can bind to GpIIB/IIIa surface proteins creating bridges between platelets and is the precursor to fibrin [8]. In addition to being involved in the coagulation cascade, fibrinogen is thought to stimulate smooth-muscle-cell migration, promote platelet aggregation and increase blood viscosity [8,9]. It has been suggested that fibrin may bind to lipoproteins in 
the vascular wall, enhancing lipid accumulation in fibrous plaques and leading to plaque growth $[8,9]$. Fibrinogen is thought to be a "downstream" marker of the inflammatory process governed by more proximal mediators (such as interleukin-6), reflecting observed spikes in circulating levels of fibrinogen during periods of inflammatory stress $[8,9]$.

Several prospective epidemiological studies have assessed the association of circulating fibrinogen concentration with CHD risk, but have yielded apparently conflicting results. In the absence of individual studies of very large size, appropriate synthesis of the available data by meta-analysis should provide a better indication of the relevance of risk markers to CHD than can individual studies typically involving just a few hundred cases. This is because meta-analyses are less likely to be subject to random error than single studies, which due to their inherent statistical uncertainties may produce false-positive and false-negative results [10]. The Fibrinogen Studies Collaboration (FSC) is an individual participant meta-analysis of data from 154,211 participants in 31 prospective studies, including 6944 firstever non-fatal myocardial infarctions or stroke events and 13,210 deaths recorded during 1.38 million personyears of follow-up (Table 1) [11]. This collaborative re-analysis of available prospective evidence on fibrinogen and cardiovascular disease risk demonstrated that about $7 \%$ of the variation in fibrinogen levels is explained by conventional vascular risk factors (notably, positive associations with smoking and body mass index and an inverse association with HDL-C) and a further $10 \%$ is explained by other inflammatory markers [12]. There were approximately log-linear relationships of circulating fibrinogen levels with risk of several vascular and non-vascular diseases including CHD, stroke, other vascular mortality and cancer mortality, with no evidence of a threshold within the range of usual fibrinogen level at any age [13]. The risk ratio for CHD per $1 \mathrm{~g} / \mathrm{L}$ increase in long-term 'average' fibrinogen concentration was 1.8 (1.6-2.1) after adjustment for several conventional vascular risk factors and correction for measurement error (Fig. 1), and did not vary materially according to sex, smoking status, level of blood pressure or blood lipids, or laboratory and study characteristics [13].

Observational studies are limited in their ability to help judge causality, particularly as they are susceptible to bias by reverse association and by confounding [14] (although such distortion of associations can be minimised, but not eliminated, by prospectively studying initially disease-free individuals and by appropri- ately adjusting risk estimates for potential known confounders). Comparison of disease rates in groups of individuals between whom the only difference is the exposure of interest, with random distribution of all other factors across the groups, should be free of such residual confounding and provide a more reliable assessment of the causal relevance of the exposure. Several interventions that lower lipid levels also influence levels of inflammatory markers. Of these, the two most studied in relation to both their impact on circulating inflammatory markers and rates of CHD are statin and fibrate medications. Since both these medications are associated with substantial changes in several markers (particularly lipids), they cannot specifically assess the causal relevance of any inflammatory marker to CHD [15]. In the absence of large-scale randomised controlled trials of suitable interventions that show specific and important changes in inflammatory markers, the study of genetic variants can provide an alternative approach to assess the causal relevance of such markers to disease risk [16]. Since the presence of particular genetic variants is effectively allocated randomly at conception, this should render associations of such variants with levels of risk markers or with coronary disease risk unaffected by subsequent development of disease (i.e. avoidance of "reverse association" bias) and, by analogy with randomized controlled trials, minimize the influence of potential confounders [16]. Identification of genetic variants that are associated with important and specific changes in circulating levels of inflammatory markers would, therefore, provide an opportunity to conduct such "Mendelian randomisation" experiments to assess the causal relevance of inflammatory markers to CHD. Several genetic determinants of fibrinogen have been identified [17], including a single nucleotide polymorphism at position -148 in the beta-fibrinogen gene promoter (beta $-148 \mathrm{C} / \mathrm{T}$ ). A meta-analysis of 20 studies of beta-fibrinogen genotypes involving a total of 12,220 coronary disease cases and 18,716 controls was reported in 2006 [18]. This investigation demonstrated that for each $\mathrm{T}$ allele inherited, carriers of beta $-148 \mathrm{C} / \mathrm{T}$ had $0.14 \mathrm{~g} / \mathrm{l}$ higher mean fibrinogen concentration, with little evidence of any important change in levels of several conventional vascular risk factors. Using data from the FSC, a $0.14 \mathrm{~g} / 1$ higher usual plasma fibrinogen concentration would be expected to be associated with a risk ratio for MI of 1.17 (95\% CI 1.14-1.19). The observed combined odds ratio for MI per $\mathrm{T}$ allele of the beta $-148 \mathrm{C} / \mathrm{T}$ polymorphism, however, was 1.00 (95\% CI 0.95-1.04) [18]. The finding that genotypes that produce (presumably) lifelong 
Table 1

Large-scale individual participant data meta-analyses of inflammatory markers and coronary heart disease

\begin{tabular}{llcc}
\hline Collaboration & \multicolumn{1}{c}{ Focus } & $\begin{array}{c}\text { Total no. of studies } \\
\text { Total no. of } \\
\text { participants }\end{array}$ & $\begin{array}{c}\text { Anticipated reporting } \\
\text { of empirical findings }\end{array}$ \\
\hline $\begin{array}{l}\text { Fibrinogen Studies Collab- } \\
\text { oration (FSC) [11-13] }\end{array}$ & $\begin{array}{l}\text { Aetiological associations and predictive } \\
\text { value of fibrinogen in prospective studies }\end{array}$ & 31 & $154 \mathrm{k}$ \\
$\begin{array}{l}\text { Emerging Risk Factors } \\
\text { Collaboration (ERFC) [27] }\end{array}$ & $\begin{array}{l}\text { Aetiological associations and predictive } \\
\text { value of CRP and other inflammatory } \\
\text { markers in prospective studies }\end{array}$ & 104 & $1.1 \mathrm{M}$ \\
$\begin{array}{l}\text { LpPLA } 2 \text { Studies Collabo- } \\
\text { ration (LSC) [46] }\end{array}$ & $\begin{array}{l}\text { Aetiological associations of LpPLA in } \\
\text { prospective studies }\end{array}$ & 32 & 2010 \\
$\begin{array}{l}\text { CRP CHD Genetics Col- } \\
\text { laboration (CCGC) [32] }\end{array}$ & $\begin{array}{l}\text { Mendelian randomisation assessment of } \\
\text { CRP }\end{array}$ & 35 & $2009-2010$ \\
\hline
\end{tabular}

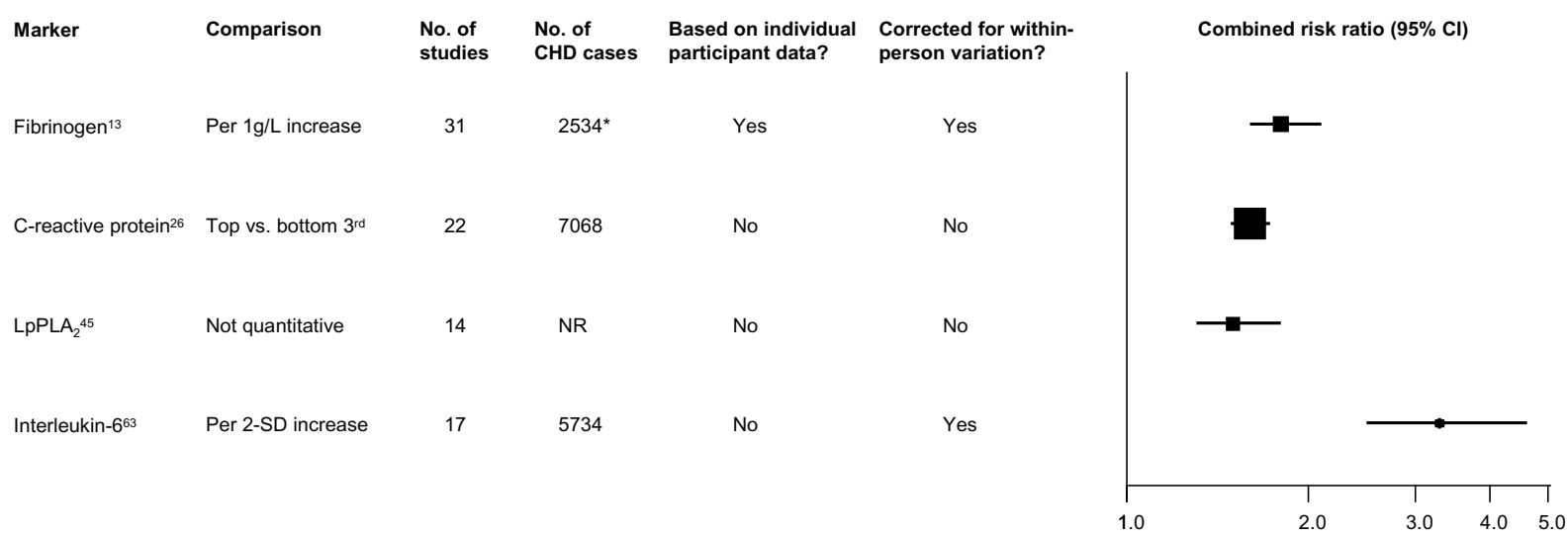

*2534 out of a total of $7118 \mathrm{CHD}$ cases had complete information on all potential confounders adjusted for NR Number of CHD cases were not reported separately from cases of any cardiovascular disease

Fig. 1. Available meta-analyses of prospective studies of circulating concentration of inflammatory markers and risk of coronary heart disease.

and specific differences in fibrinogen concentration are not materially associated with CHD risk, together with the non-specific associations of fibrinogen levels with risk of several chronic vascular and non-vascular diseases [13], suggest that fibrinogen is unlikely to be causal in coronary disease.

Although many published prospective studies have commented on the potential value of particular markers in risk prediction, they have often reported on measures of strength of association only (e.g., odds ratios, hazard ratios), which do not directly address the accuracy of a marker in risk prediction or stratification. Instead, such accuracy is commonly assessed by two independent criteria, discrimination and calibration. Discrimination is the ability to separate individuals at higher risk from those at lower risk, while calibration is the ability to correctly estimate the risk or probability of a future event [19]. Each of these approaches may impart somewhat different information. To date, prospective studies that have used such methods to assess the potential improvement in vascular risk prediction upon measurement of fibrinogen levels in addition to con- ventional vascular risk factors have yielded conflicting results [20-23]. Relevant investigations in the FSC should help provide a more robust assessment about whether measurement of circulating fibrinogen concentration can help better identify individuals at increased risk of $\mathrm{CHD}$ than measurement of conventional risk factors alone.

\section{C-reactive protein (CRP)}

CRP, a nonglycosylated 224-residue plasma protein, is probably the most studied circulating marker of inflammation. Produced by hepatocytes, CRP synthesis is closely regulated by upstream pro-inflammatory cytokines (such as interleukin-6) and resultantly massive spikes in circulating CRP levels are observed in response to inflammatory stimuli [24]. Whereas older less sensitive assays were only able to identify such acute phase responses of CRP (during which levels of CRP can rise up to several-thousand fold), more recent "high sensitivity" immunoassay methods have en- 
abled measurement of circulating "baseline" levels and assessment of chronic low-grade inflammation [24].

The first population-based prospective study of circulating CRP concentration and incident CHD risk, reported in 1996, was a nested case-control comparison of 246 CHD cases and 491 controls within The Multiple Risk Factor Intervention Trial [25]. Since this study, more than 40 such studies of CRP and CHD risk have been reported. A literature-based meta-analysis of 22 prospective epidemiological studies published by 2004 , involving a total of 7068 incident CHD cases, reported a combined risk ratio for CHD of $1.6(1.5-1.7)$ in a comparison of individuals in the top third with those in the bottom third of the baseline distribution of CRP concentration in the population [26] (Fig. 1). It remains unclear, however, whether associations of CRP levels with incident CHD risk are "independent" from conventional vascular risk factors and other inflammatory markers, specific to CHD (or vascular disease), or importantly modified under different circumstances (such as by age, sex, smoking status or different levels of conventional vascular risk factors). The Emerging Risk Factors Collaboration (ERFC) is an individual participant meta-analysis of data from 110 prospective cohorts which builds on the FSC [27]. It has established a central database in which individual data records from over 1.1 million participants have been harmonised to a consistent format, including from large subsets of participants with information on inflammatory (including CRP) and other emerging risk markers, lipids and other conventional risk factors and characteristics, as well as major cardiovascular morbidity and cause-specific mortality (Table 1) [27]. Information on repeat measurements on relevant characteristics has been collected in approximately 320,000 participants to enable estimation of and adjustment for within-person variability in measured values. This collaborative initiative should enable more precise and detailed characterisation than has previously been possible of the shape and strength of the age- and sex-specific associations of circulating CRP levels with incident CHD outcomes under a wide range of circumstances [27].

Several genetic variants in the CRP gene that control CRP concentration have been identified [28]. A metaanalysis of studies of the $+1444 \mathrm{C}>\mathrm{T}$ polymorphism in the CRP gene assessed the association of this variant with circulating CRP concentration and CHD in a total of 18,637 participants, including 4610 CHD cases [29]. This meta-analysis reported that the combined geometric mean CRP was 1.14 (1.11-1.18) higher per each $\mathrm{T}$ allele inherited, with negligible difference in levels of several conventional vascular risk factors [29]. The association of the same variant with CHD risk was 0.96 (0.90-1.03) per T allele [29]. A separate study assessed associations of 4 different variants in the CRP gene $(1081 \mathrm{G}>\mathrm{A}, 223 \mathrm{C}>\mathrm{T},-390 \mathrm{C}>\mathrm{T}>\mathrm{A}, 3678 \mathrm{~T}>\mathrm{G})$ in a total of over 50,000 participants (including 6545 with CHD) [30]. A combination of these 4 variants was associated with a $64 \%$ increase in circulating CRP concentration and, based on the observed association of CRP levels with CHD risk, was predicted to be associated with a $32 \%$ increase in CHD risk [30]. The same genetic combination, however, was not significantly associated with CHD [30]. These findings from studies of CRP genotypes do not support a causal association of $\mathrm{CRP}$ in CHD. However, as any associations of common genetic variants with disease risk are likely to be modest, genetic studies require information from upward of 15,000 patients with coronary disease to reliably evaluate the likelihood and magnitude of any causal association between CRP and CHD risk [31]. The CRP CHD Genetics Collaboration (CCGC) has established a central database containing individual data on CRP polymorphisms, circulating CRP levels and major coronary outcomes as well as several other relevant characteristics [32] (Table 1). This collaboration comprises a total of over 37,000 CHD outcomes and over 120,000 controls in 35 studies and should help clarify whether CRP is involved in the pathogenesis of CHD [32]. Study of interventions that specifically modify circulating CRP levels may help directly assess whether CRP is likely to be causal in CHD. Although such interventions are in development, these interventions currently focus on whether anti-CRP agents may have a role in minimising tissue damage subsequent to an MI (rather than help prevent development of CHD) [33].

Several prospective studies have reported on the potential utility of CRP measurements for CHD risk prediction. A recent review assessed the predictive performance of CRP in two prospective cohort studies (involving a total of 309 CHD outcomes) and reported a systematic review of relevant data from 31 published prospective studies (involving a total of 11,252 CHD outcomes) [34]. This review concluded that although raised circulating CRP levels are consistently associated with increased CHD risk, measurement of CRP levels provides little improvement in CHD risk prediction when assessed using several metrics of predictive value [34]. Despite such reservations stemming from findings from observational studies, there has been substantial interest in whether measurement of CRP levels should be used for risk stratification and prioritiza- 
tion of preventative treatment in individuals who, according to current clinical guidelines, would otherwise be ineligible for such treatment [35]. The Justification for the Use of Statins in Prevention: an Intervention Trial Evaluating Rosuvasatin (JUPITER) trial randomly assigned 17,802 men and women with LDL-C levels $<3.4 \mathrm{mmol} / \mathrm{L}$ (ie, below thresholds for treatment according to current clinical guidelines) and highsensitivity CRP levels $\geqslant 2.0 \mathrm{mmol} / \mathrm{L}$ to receive $20 \mathrm{mg}$ rosuvastatin or placebo [36]. The trial was stopped after a median follow-up of 1.9 years, with an observed reduction in LDL-C and CRP of 50\% and 37\%, respectively, in people receiving rosuvastatin. The hazard ratio for MI in this trial was $0.46(0.30-0.70)$ in people receiving rosuvastatin compared to people receiving placebo [36]. A separate report from the JUPITER trial reported that compared to participants receiving placebo, the hazard ratio for a combination of any of non-fatal MI, non-fatal stroke, unstable angina, revascularization or cardiovascular death in participants allocated to receive rosuvastatin was: $0.45(0.34-0.60)$ in people who achieved LDL-C $<1.8 \mathrm{mmol} / \mathrm{L} ; 0.38$ (0.26-0.56) in people who achieved CRP $<2 \mathrm{mg} / \mathrm{L}$; and $0.35(0.23-0.54)$ in people who achieved LDL-C $<1.8 \mathrm{mmol} / \mathrm{L}$ and CRP $<2 \mathrm{mg} / \mathrm{L}$ [37]. As acknowledged in this report, however, such assessments are no longer randomized and, therefore, potentially susceptible to distortion by confounding [37]. Assessment of the relevance of CRP levels in other long-term trials of statin medications are ongoing [38].

\section{Lipoprotein-associated phospholipase $A_{2}$ (Lp-PLA $\left.\mathbf{A}_{2}\right)$}

Originally named platelet-activating factor acetylhydrolase after its ability to catalyse the hydrolysis of platelet-activating factor in vitro, Lp-PLA ${ }_{2}$ appears to link arterial retention and oxidative modification of LDL in the coronary artery wall with localised inflammation and subsequent plaque destabilization [39]. Expressed by hematopoietic cells, around 70-80\% of Lp$\mathrm{PLA}_{2}$ is carried on LDL [40]. By virtue of this association, $\mathrm{Lp}-\mathrm{PLA}_{2}$ is carried into the arterial wall where it can hydrolyze the $s n-2$ fatty acids in the phospholipids of LDL as they become truncated by oxidation [41]. For example, Lp-PLA ${ }_{2}$ mediates the oxidative modification of phosphatidylcholine (a common phospholipid in LDL) and its subsequent hydrolysis to lysophosphatidylcholine and oxidized free fatty acids. These products elicit several potentially proinflammatory and proatherogenic effects [42]. In turn, inflammatory cells attracted to the arterial wall by the products of Lp-PLA 2 activity express further Lp-PLA $A_{2}$, potentially creating a positive feedback loop [43]. On the other hand, Lp$\mathrm{PLA}_{2}$ has also been proposed to play a protective role against atherosclerosis, based on the observation that its substrates (rather than the products it generates) can show proinflammatory and proatherogenic activities [44].

Despite ongoing debate over the role of $\mathrm{Lp}_{\mathrm{PLA}}$ in atherosclerosis, several prospective epidemiological studies have reported generally positive associations between circulating levels of Lp-PLA 2 and subsequent risk of cardiovascular disease. A literature-based metaanalysis of 14 observational studies reported a relative risk of 1.5 (1.3-1.8) for Lp-PLA 2 and cardiovascular disease risk [45] (Fig. 1). The validity of that metaanalysis was limited, however, because it combined information from prospective and retrospective studies (increasing the potential for selection and reverse association biases); considered heterogeneous populations, disease outcomes and Lp-PLA 2 exposures (potentially conflating any divergent associations); and did not standardize reported risk estimates to a consistent comparison [45]. The relevance of Lp-PLA ${ }_{2}$ to CHD risk remains uncertain. In particular, the magnitude and shape of any dose-response relationships, the extent of any coronary or vascular specificity, and the degree of independence from conventional cardiovascular risk factors (particularly the lipoproteins on which Lp-PLA 2 is carried) have yet to be characterized in detail. The Lp-PLA $_{2}$ Studies Collaboration (LSC) is a consortium of investigators of prospective studies of Lp-PLA 2 and cardiovascular disease [46] (Table 1). The LSC will include data from 32 prospective studies involving a total of approximately 15000 patients with major cardiovascular disease outcomes and should help to determine more reliably than previously possible the strength and shape of any independent association, the magnitude of associations in different circumstances, and sources of heterogeneity between studies [46].

Family studies have suggested that around half of the variation in Lp-PLA 2 activity may be heritable [47], and several common variants in the Lp-PLA 2 gene (PLA2G7 on chromosome 6) have now been identified. One such variant, V279F is found almost exclusively in East Asian populations and results in Lp$\mathrm{PLA}_{2}$ activity being significantly reduced in heterozygotes and almost undetectable in individuals homozygous for the T allele [48]. In contrast to V279F which has only been reported in East Asian populations, oth- 
er common PLA2G7 variants have been found in all populations [49] and Mendelian randomization experiments (such as those described above) involving study of these variants may provide a framework to help judge whether Lp-PLA 2 is causal in CHD.

Because circulating Lp-PLA 2 levels have generally been positively associated with cardiovascular diseases in published prospective studies, a consensus panel recently recommended the incorporation of Lp-PLA 2 mass measurement into risk assessment guidelines for individuals at 'intermediate' risk of CHD [50]. As noted above, however, assessments of the magnitude and independence of associations with disease outcomes do not directly address the potential utility of a risk marker in classifying or predicting disease risk. The few previous studies to have directly assessed the predictive ability of Lp-PLA $A_{2}$ in vascular disease have reported generally modest improvements in risk prediction on addition of Lp-PLA 2 to conventional risk factors [51-55]. Interpretation of these findings has been complicated, however, by the fact that these relatively few studies have used different population settings and endpoints; have added Lp-PLA 2 to risk prediction models that include different sets of conventional cardiovascular risk factors; have typically involved fewer than 10 years of follow-up; and have generally used the area under the receiver-operator characteristic curve (AUROC) to assess discrimination, a technique that is only appropriate for binary data and does not consider time to event or allow for censoring. Furthermore, these previous studies did not evaluate the ability of Lp-PLA 2 measurements to reclassify predicted CHD risk; analyses that may be more clinically informative than discrimination $\mathrm{per}$ $s e$. Future prospective studies with long-term followup in large numbers of initially healthy participants are therefore needed to help clarify the value of Lp-PLA 2 measurements to cardiovascular risk prediction.

A number of studies have shown that medications that lower lipid levels and reduce CHD risk also lower Lp-PLA ${ }_{2}$. For example, statins lower Lp-PLA 2 activity by around $20-40 \%$ [56]. However, because statins do not limit secretion of Lp-PLA 2 from macrophages, the observed reductions in Lp-PLA 2 activity are thought to result from drug-induced enhanced clearance of LDL [57]. By contrast, darapladib (SB480848; GlaxoSmithKline), a reversible substrate-competitive pyrimidone, reduces Lp-PLA 2 activity by around two thirds (with more modest effects on Lp-PLA 2 mass) [58]. In late 2008 the STABILITY (Stabilisation of Atherosclerotic plaque By Initiation of darapLadib TherapY) trial was initiated [59]. This randomised, placebo- controlled trial will assess the impact of long-term treatment with darapladib compared to placebo on the composite endpoint of major cardiovascular events (including cardiovascular death, nonfatal MI and nonfatal stroke) in over 15,000 CHD patients receiving standard care [59], and help elucidate the importance of Lp$\mathrm{PLA}_{2}$ inhibition therapy to the secondary prevention of CHD.

\section{Interleukin-6 (IL-6)}

IL-6, a pleiotropic 184-amino acid monomer, is secreted by $\mathrm{T}$ cells, macrophages and endothelial cells and propogates inflammatory cascades in response to inflammatory stimuli [60,61]. IL-6 can either accelerate or inhibit the inflammatory process. Part of the role of IL-6 in the acute phase response is to upregulate several downstream markers, including CRP [60, 61]. IL-6 levels are also elevated in response to muscle contraction, produced by smooth muscle cells in blood vessels and may have a role in lipid catabolism and insulin resistance [60,61]. Excess circulating IL-6 concentration has been linked to several autoimmune disorders, especially rheumatoid arthiritis [62].

Although less studied than its down-stream acute phase reactants such as fibrinogen and CRP, several prospective studies have reported associations of circulating IL-6 concentration with CHD risk. A literaturebased meta-analysis of 17 prospective epidemiological studies published by 2008, involving a total of 5730 CHD cases recorded during follow-up, reported a combined risk ratio for CHD of 1.6 (1.4-1.8) per 2-SD increase in baseline IL-6 measurements [63]. However, owing to the short half-life and substantial withinindividual fluctuations in circulating IL-6 levels, failure to make allowance for such within-individual variation may substantially underestimate the magnitude of any association of IL- 6 concentration with CHD risk. After correction for within-individual variability of IL-6, the combined risk ratio for $\mathrm{CHD}$ in this meta-analysis was 3.3 (2.5-4.6) per 2-SD increase in IL-6 levels [63] (Fig. 1); potentially comparable to the strength of observed associations of some conventional vascular risk factors with CHD risk. Further studies of IL-6 concentration and CHD risk are warranted, therefore, to confirm such associations and to assess whether measurement of IL-6 levels can usefully contribute to CHD risk prediction algorithms. Studies of genetic variants in the IL-6 gene have predominantly focused on the $-174 \mathrm{G}>\mathrm{C}$ promoter variant, but this variant does not 
appear to be materially associated with circulating IL6 concentration $[64,65]$ (so is unlikely to provide any causal inference about the relevance of IL-6 levels to CHD). Several IL-6 receptor antagonists are under development and are being trialed for the treatment of rheumatoid arthritis [62,66]. Such trials may help indicate whether anti-IL-6 therapy may also be a potential therapeutic target for CHD prevention.

\section{Other markers of inflammation}

Several other markers of inflammation have also been assessed in relation to CHD, including albumin [67], leukocyte count [68] (both of which are being assessed in the ERFC), CD40 ligand [69], tumour necrosis factor alpha [70], matrix metalloproteinases [71], IL-1 [72] and IL-18 [73]. Ongoing studies of these and other related markers of inflammation should help progress understanding of the potential relevance of such markers to CHD.

\section{Summary}

Although it is generally accepted that inflammation is importantly involved in the development of CHD, it remains unclear whether circulating markers of inflammation are causal or whether their measurement can help improve CHD risk prediction. Ongoing largescale epidemiological and genetic studies should help to resolve such outstanding uncertainties.

\section{References}

[1] World Health Organization, The global burden of disease: 2004 update, WHO, 2008.

[2] V. Fuster and A. Lewis, Conner Memorial Lecture. Mechanisms leading to myocardial infarction: insights from studies of vascular biology, Circulation 90(4) (October 1994), 21262146.

[3] C.K. Chow, A.C. Pell, A. Walker, C. O'Dowd, A.F. Dominiczak and J.P. Pell, Families of patients with premature coronary heart disease: an obvious but neglected target for primary prevention, BMJ 335(7618) (8 Sep 2007), 481-485.

[4] M. Marmot and S.L. Syme, Acculturation and coronary heart disease in Japanese-Americans, AJE 104 (1976), 225-247.

[5] D.J. Hunter, Gene-environment interactions in human diseases, Nat Rev Genet 6 (2005), 287-298.

[6] G.K. Hansson, Inflammation, atherosclerosis, and coronary artery disease, $N$ Engl J Med 352(16) (21 Aprl 2005), 16851695.

[7] R. Ross, Atherosclerosis - an inflammatory disease, N Engl J Med 340(2) (14 January 1999), 115-126.
[8] M.W. Mosesson, Fibrinogen and fibrin structure and functions, J Thromb Haemost 3(8) (August 2005), 1894-1904.

[9] E. Ernst and W. Koenig, Fibrinogen and cardiovascular risk, Vasc Med 2(2) (1997), 115-125.

[10] G. Davey Smith, M. Egger and A.N. Phillips, Meta-analysis, Beyond the grand mean? BMJ 315(7122) (13 Dec 1997), 1610-1614.

[11] Fibrinogen Studies Collaboration, Collaborative metaanalysis of prospective studies of plasma fibrinogen and cardiovascular disease, Eur J Cardiovasc Prev Rehabil 11(1) (Feb 2004), 9-17.

[12] Fibrinogen Studies Collaboration, Associations of plasma fibrinogen levels with established cardiovascular disease risk factors, inflammatory markers, and other characteristics: individual participant meta-analysis of 154,211 adults in 31 prospective studies: the fibrinogen studies collaboration, Am J Epidemiol 166(8) (15 Oct 2007), 867-879.

[13] Fibrinogen Studies Collaboration, Plasma fibrinogen level and the risk of major cardiovascular diseases and nonvascular mortality: an individual participant meta-analysis, JAMA 294(14) (12 Oct 2005), 1799-1809.

[14] D.B. Petitti and D.A. Freedman, How far can epidemiologists get with statistical adjustment? Am J Epidemiol 162 (2005), 415-418.

[15] D. Preiss and N. Sattar, Lipids, lipid modifying agents and cardiovascular risk: a review of the evidence, Clin Endocrinol 70 (2009), 815-828.

[16] G. Davey Smith and S. Ebrahim, 'Mendelian randomization': can genetic epidemiology contribute to understanding environmental determinants of disease? Int J Epidemiol 32 (2003), $1-22$.

[17] A. Dehghan, Q. Yang, A. Peters, S. Basu, J.C. Bis, A.R. Rudnicka, M. Kavousi, M.-H. Chen, J. Baumert, G.D.O. Lowe, B. McKnight, W. Tang, M. de Maat, M.G. Larson, S. Eyhermendy, W.L. McArdle, T. Lumley, J.S. Pankow, A. Hofman, J.M. Massaro, F. Rivadeneira, M. Kolz, K.D. Taylor, C.M. van Duijn, S. Kathiresan, T. Illig, Y.S. Aulchenko, K.A. Volcik, A.D. Johnson, A.G. Uitterlinden, G.H. Tofler, C. Gieger, W. Trust Case Control Consortium, B.M. Psaty, D.J. Couper, E. Boerwinkle, W. Koenig, C.J. O’Donnell, J.C. Witteman, D.P. Strachan, N.L. Smith and A.R. Folsom, Association of Novel Genetic Loci With Circulating Fibrinogen Levels: A GenomeWide Association Study in 6 Population-Based Cohorts, Circ Cardiovasc Genet 2 (2009), 125-133.

[18] B. Keavney, J. Danesh, S. Parish et al., Fibrinogen and coronary heart disease: test of causality by 'Mendelian randomization', Int J Epidemiol 35 (2006), 935-943.

[19] N.R. Cook, Statistical evaluation of prognostic versus diagnostic models: beyond the ROC curve, Clin Chem 54(1) (January 2008), 17-23.

[20] M. Woodward, P. Welsh, A. Rumley, H. Tunstall-Pedoe and G.D. Lowe, Do inflammatory biomarkers add to the discrimination of cardiovascular disease after allowing for social deprivation? Results from a 10 year cohort study in Glasgow, Scotland, Eur Heart J (10 Apr 2009).

[21] J.W. Bartlett, B.L. De Stavola and T.W. Meade, Assessing the contribution of fibrinogen in predicting risk of death in men with peripheral arterial disease, J Thromb Haemost 7 (2009), 270-276.

[22] A. Smith, C. Patterson, J. Yarnell, A. Rumley, Y. Ben-Shlomo and G. Lowe, Which hemostatic markers add to the predictive value of conventional risk factors for coronary heart disease and ischemic stroke? The Caerphilly Study, Circulation 112 (2005), 3080-3087. 
[23] T.J. Wang, P. Gona, M.G. Larson et al., Multiple Biomarkers for the Prediction of First Major Cardiovascular Events and Death, N Engl J Med 355 (2006), 2631-2639.

[24] J.P. Casas, T. Shah, A.D. Hingorani, J. Danesh and M.B. Pepys, C-reactive protein and coronary heart disease: a critical review, J Intern Med 264(4) (Oct 2008), 295-314.

[25] L.H. Kuller, R.P. Tracy, J. Shaten and E.N. Meilahn, Relation of C-reactive protein and coronary heart disease in the MRFIT nested case-control study. Multiple Risk Factor Intervention Trial, Am J Epidemiol 144(6) (15 Sep 1996), 537-547.

[26] J. Danesh, J.G. Wheeler, G.M. Hirschfield, S. Eda, G. Eiriksdottir, A. Rumley, G.D. Lowe, M.B. Pepys and V. Gudnason, C-reactive protein and other circulating markers of inflammation in the prediction of coronary heart disease, $N$ Engl J Med 350(14) (1 Aprl 2004), 1387-1397.

[27] Emerging Risk Factors Collaboration, The Emerging Risk Factors Collaboration: analysis of individual data on lipid, inflammatory and other markers in over 1.1 million participants in 104 prospective studies of cardiovascular diseases, Eur J Epidemiol 22 (2007), 839-869.

[28] C. Verzilli, T. Shah, J.P. Casas et al., Bayesian meta-analysis of genetic association studies with different sets of markers, Am J Hum Genet 82 (2008), 859-872.

[29] D.A. Lawlor, R.M. Harbord, N.J. Timpson, G.D. Lowe, A. Rumley, T.R. Gaunt, I. Baker, J.W. Yarnell, M. Kivimäki, M. Kumari, P.E. Norman, K. Jamrozik, G.J. Hankey, O.P. Almeida, L. Flicker, N. Warrington, M.G. Marmot, Y. BenShlomo, L.J. Palmer, I.N. Day, S. Ebrahim and G.D. Smith, The association of C-reactive protein and CRP genotype with coronary heart disease: findings from five studies with 4,610 cases amongst 18,637 participants, PLoS ONE 3(8) (20 Aug 2008), e3011.

[30] J. Zacho, A. Tybjaerg-Hansen, J.S. Jensen, P. Grande, H. Sillesen and B.G. Nordestgaard, Genetically elevated C-reactive protein and ischemic vascular disease, $N$ Engl J Med 359(18) (30 Oct 2008), 1897-1908.

[31] J.P. Ioannidis, M. Gwinn, J. Little, J.P. Higgins, J.L. Bernstein, P. Boffetta, M. Bondy, M.S. Bray, P.E. Brenchley, P.A. Buffler, J.P. Casas, A. Chokkalingam, J. Danesh, G.D. Smith, S. Dolan, R. Duncan, N.A. Gruis, P. Hartge, M. Hashibe, D.J. Hunter, M.R. Jarvelin, B. Malmer, D.M. Maraganore, J.A. NewtonBishop, T.R. O’Brien, G. Petersen, E. Riboli, G. Salanti, D. Seminara, L. Smeeth, E. Taioli, N. Timpson, A.G. Uitterlinden, P. Vineis, N. Wareham, D.M. Winn, R. Zimmern and M.J. Khoury, Human Genome Epidemiology Network and the Network of Investigator Networks, A road map for efficient and reliable human genome epidemiology, Nat Genet $\mathbf{3 8}(1)$ (Jan 2006), 3-5

[32] CRP CHD Genetics Collaboration, Collaborative pooled analysis of data on C-reactive protein gene variants and coronary disease: judging causality by Mendelian randomisation, Eur J Epidemiol 23(8) (2008), 531-540.

[33] M.B. Pepys, G.M. Hirschfield, G.A. Tennent, J.R. Gallimore, M.C. Kahan, V. Bellotti, P.N. Hawkins, R.M. Myers, M.D. Smith, A. Polara, A.J. Cobb, S.V. Ley, J.A. Aquilina, C.V. Robinson, I. Sharif, G.A. Gray, C.A. Sabin, M.C. Jenvey, S.E. Kolstoe, D. Thompson and S.P. Wood, Targeting C-reactive protein for the treatment of cardiovascular disease, Nature 440(7088) (27 Apr 2006), 1217-1221.

[34] T. Shah, J.P. Casas, J.A. Cooper, I. Tzoulaki, R. Sofat, V. McCormack, L. Smeeth, J.E. Deanfield, G.D. Lowe, A. Rumley, F.G. Fowkes, S.E. Humphries and A.D. Hingorani, Critical appraisal of CRP measurement for the prediction of coronary heart disease events: new data and systematic review of 31 prospective cohorts, Int J Epidemiol 38(1) (Feb 2009), 217231.

[35] L. Mosca, C-reactive protein-to screen or not to screen? $N$ Engl J Med 347(20) (14 Nov 2002), 1615-1617.

[36] P.M. Ridker, E. Danielson, F.A. Fonseca, J. Genest, A.M. Gotto Jr., J.J. Kastelein, W. Koenig, P. Libby, A.J. Lorenzatti, J.G. MacFadyen, B.G. Nordestgaard, J. Shepherd, J.T. Willerson and R.J. Glynn, JUPITER Study Group, Rosuvastatin to prevent vascular events in men and women with elevated Creactive protein, $N$ Engl J Med 359(21) (20 Nov 2008), 21952207.

[37] P.M. Ridker, E. Danielson, F.A. Fonseca, J. Genest, A.M. Gotto Jr., J.J. Kastelein, W. Koenig, P. Libby, A.J. Lorenzatti, J.G. Macfadyen, B.G. Nordestgaard, J. Shepherd, J.T. Willerson and R.J. Glynn, JUPITER Trial Study Group, Reduction in Creactive protein and LDL cholesterol and cardiovascular event rates after initiation of rosuvastatin: a prospective study of the JUPITER trial, Lancet 373(9670) (4 Apr 2009), 1175-1182.

[38] Heart Protection Study Collaborative Group, MRC/ BHF Heart Protection Study of cholesterol lowering with simvastatin in 20,536 high-risk individuals: a randomized placebocontrolled trial, Lancet 360 (2002), 7-22.

[39] D.M. Stafforini, Biology of platelet-activating factor acetylhydrolase (PAF-AH, lipoprotein associated phospholipase A2), Cardiovasc Drugs Ther 23(1) (February 2009), 73-83.

[40] D.M. Stafforini, L.W. Tjoelker, S.P. McCormick et al., Molecular basis of the interaction between plasma platelet-activating factor acetylhydrolase and low density lipoprotein, $J$ Biol Chem 274(11) (12 March 1999), 7018-7024.

[41] J.P. McConnell and D.M. Hoefner, Lipoprotein-associated phospholipase A2, Clin Lab Med 26(3) (September 2006), 679-697, vii.

[42] A. Zalewski and C. Macphee, Role of lipoprotein-associated phospholipase A2 in atherosclerosis: biology, epidemiology, and possible therapeutic target, Arterioscler Thromb Vasc Biol 25(5) (May 2005), 923-931.

[43] A. Lerman and J.P. McConnell, Lipoprotein-associated phospholipase A2: a risk marker or a risk factor? Am J Cardiol 101(12A) (16 June 2008), 11F-22F.

[44] S.A. Karabina and E. Ninio, Plasma PAF-acetylhydrolase: an unfulfilled promise? Biochim Biophys Acta 1761(11) (November 2006), 1351-1358.

[45] C.A. Garza, V.M. Montori, J.P. McConnell, V.K. Somers, I.J. Kullo and F. Lopez-Jimenez, Association between lipoproteinassociated phospholipase A2 and cardiovascular disease: a systematic review, Mayo Clin Proc 82(2) (2007 February), 159-165.

[46] The Lp-PLA2 Studies Collaboration, Collaborative metaanalysis of individual participant data from observational studies of Lp-PLA2 and cardiovascular diseases, Eur J Cardiovasc Prev Rehabil 14(1) (Feb 2007), 3-11.

[47] R. Guerra, B. Zhao, V. Mooser, D. Stafforini, J.M. Johnston and J.C. Cohen, Determinants of plasma platelet-activating factor acetylhydrolase: heritability and relationship to plasma lipoproteins, J Lipid Res 38(11) (November 1997), 22812288.

[48] D.M. Stafforini, K. Satoh, D.L. Atkinson, L.W. Tjoelker, C. Eberhardt, H. Yoshida, T. Imaizumi, S. Takamatsu, G.A. Zimmerman, T.M. McIntyre, P.W. Gray and S.M. Prescott, Platelet-activating factor acetylhydrolase deficiency, A missense mutation near the active site of an anti-inflammatory phospholipase, J Clin Invest 97(12) (15 Jun 1996), 2784-2791.

[49] M.M. Hoffmann, K. Winkler, W. Renner et al., Genetic variants and haplotypes of lipoprotein associated phospholipase 
A2 and their influence on cardiovascular disease (The Ludwigshafen Risk and Cardiovascular Health Study), J Thromb Haemost 7(1) (2009 January), 41-48.

[50] M.H. Davidson, M.A. Corson, M.J. Alberts et al., Consensus panel recommendation for incorporating lipoproteinassociated phospholipase A2 testing into cardiovascular disease risk assessment guidelines, Am J Cardiol 101(12A) (16 June 2008), 51F-57F.

[51] A.R. Folsom, L.E. Chambless, C.M. Ballantyne et al., An assessment of incremental coronary risk prediction using $\mathrm{C}$ reactive protein and other novel risk markers: the atherosclerosis risk in communities study, Arch Intern Med 166(13) (10 July 2006), 1368-1373.

[52] L.B. Daniels, G.A. Laughlin, M.J. Sarno, R. Bettencourt, R.L. Wolfert and E. Barrett-Connor, Lipoprotein-associated phospholipase A2 is an independent predictor of incident coronary heart disease in an apparently healthy older population: the Rancho Bernardo Study, J Am Coll Cardiol 51(9) (4 March 2008), 913-919.

[53] K. Winkler, M.M. Hoffmann, B.R. Winkelmann et al., Lipoprotein-associated phospholipase A2 predicts 5-year cardiac mortality independently of established risk factors and adds prognostic information in patients with low and medium high-sensitivity C-reactive protein (the Ludwigshafen risk and cardiovascular health study), Clin Chem 53(8) (August 2007), 1440-1447.

[54] W. Koenig, D. Twardella, H. Brenner and D. Rothenbacher, Lipoprotein-associated phospholipase A2 predicts future cardiovascular events in patients with coronary heart disease independently of traditional risk factors, markers of inflammation, renal function, and hemodynamic stress, Arterioscler Thromb Vasc Biol 26(7) (July 2006), 1586-1593.

[55] Y. Gerber, J.P. McConnell, A.S. Jaffe, S.A. Weston, J.M. Killian and V.L. Roger, Lipoprotein-associated phospholipase A2 and prognosis after myocardial infarction in the community, Arterioscler Thromb Vasc Biol 26(11) (November 2006), 2517-2522.

[56] C.J. Packard, D.S. O’Reilly, M.J. Caslake et al., Lipoproteinassociated phospholipase A2 as an independent predictor of coronary heart disease, West of Scotland Coronary Prevention Study Group, NEngl J Med 343(16) (19 October 2000), 11481155.

[57] V. Tsimihodimos, S.A. Karabina, A.P. Tambaki et al., Atorvastatin preferentially reduces LDL-associated platelet-activating factor acetylhydrolase activity in dyslipidemias of type IIA and type IIB, Arterioscler Thromb Vasc Biol 22(2) (1 February 2002), 306-311.

[58] E.R. Mohler, III, C.M. Ballantyne, M.H. Davidson et al., The effect of darapladib on plasma lipoprotein-associated phospholipase A2 activity and cardiovascular biomarkers in patients with stable coronary heart disease or coronary heart disease risk equivalent: the results of a multicenter, randomized, double-blind, placebo-controlled study, J Am Coll Cardiol 51(17) (29 April 2008), 1632-1641.

[59] The Stabilization of Atherosclerotic Plaque by Initiation of Darapladib Therapy Trial (STABILITY), http://clinicaltrials. gov/ct2/show/NCT00799903, Accessed, 29 March 2009.

[60] M.Y. Abeywardena, W.R. Leifert, K.E. Warnes, J.N. Varghese and R.J. Head, Cardiovascular biology of interleukin-6, Curr Pharm Des 15(15) (2009), 1809-1821.
[61] J.S. Yudkin, M. Kumari, S.E. Humphries and V. MohamedAli, Inflammation, obesity, stress and coronary heart disease: is interleukin-6 the link? Atherosclerosis 148(2) (Feb 2000), 209-214.

[62] N. Nishimoto, Interleukin-6 in rheumatoid arthritis, Curr Opin Rheumatol 18(3) (May 2006), 277-281.

[63] J. Danesh, S. Kaptoge, A.G. Mann, N. Sarwar, A. Wood, S.B. Angleman, F. Wensley, J.P. Higgins, L. Lennon, G. Eiriksdottir, A. Rumley, P.H. Whincup, G.D. Lowe and V. Gudnason, Long-term interleukin-6 levels and subsequent risk of coronary heart disease: two new prospective studies and a systematic review, PLoS Med 5(4) (8 Apr 2008), e78.

[64] M.P. Sie, F.A. Sayed-Tabatabaei, H.H. Oei, A.G. Uitterlinden, H.A. Pols, A. Hofman, C.M. van Duijn and J.C. Witteman, Interleukin $6-174 \mathrm{~g} / \mathrm{c}$ promoter polymorphism and risk of coronary heart disease: results from the rotterdam study and a meta-analysis, Arterioscler Thromb Vasc Biol 26(1) (Jan 2006), 212-217.

[65] C. Huth, T. Illig, C. Herder, C. Gieger, H. Grallert, C. Vollmert, W. Rathmann, Y.H. Hamid, O. Pedersen, T. Hansen, B. Thorand, C. Meisinger, A. Doring, N. Klopp, H. Gohlke, W. Lieb, C. Hengstenberg, V. Lyssenko, L. Groop, H. Ireland, J.W. Stephens, I. Wernstedt Asterholm, J.O. Jansson, H. Boeing, M. Mohlig, H.M. Stringham, M. Boehnke, J. Tuomilehto, J.M. Fernandez-Real, A. Lopez-Bermejo, L. Gallart, J. Vendrell, S.E. Humphries, F. Kronenberg, H.E. Wichmann and I.M. Heid, Joint analysis of individual participants' data from 17 studies on the association of the IL6 variant $-174 \mathrm{G}>\mathrm{C}$ with circulating glucose levels, interleukin-6 levels, and body mass index, Ann Med 41(2) (2009), 128-138.

[66] S.L. Plushner, Tocilizumab: an interleukin-6 receptor inhibitor for the treatment of rheumatoid arthritis, Ann Pharmacother 42(11) (Nov 2008), 1660-1668.

[67] J. Danesh, P. Whincup, M. Walker, L. Lennon, A. Thomson, P. Appleby, J.R. Gallimore and M.B. Pepys, Low grade inflammation and coronary heart disease: prospective study and updated meta-analyses, BMJ 321(7255) (22 Jul 2000), 199-204.

[68] J.G. Wheeler, M.E. Mussolino, R.F. Gillum and J. Danesh, Associations between differential leucocyte count and incident coronary heart disease: 1764 incident cases from seven prospective studies of 30,374 individuals, Eur Heart J 25(15) (Aug 2004), 1287-1292.

[69] D. Vishnevetsky, V.A. Kiyanista and P.J. Gandhi, CD40 ligand: a novel target in the fight against cardiovascular disease, Ann Pharmacother 38(9) (Sep 2004), 1500-1508.

[70] C. Popa, M.G. Netea, P.L. van Riel, J.W. van der Meer and A.F. Stalenhoef, The role of TNF-alpha in chronic inflammatory conditions, intermediary metabolism, and cardiovascular risk, J Lipid Res 48(4) (Apr 2007), 751-762.

[71] R.J. MacFadyen, Can matrix metalloproteinase inhibitors provide a realistic therapy in cardiovascular medicine? Curr Opin Pharmacol 7(2) (Apr 2007), 171-178.

[72] B. Vicenová, V. Vopálenský, L. Burýšek and M. Pospíšek, Emerging role of interleukin-1 in cardiovascular diseases, Physiol Res 17 Dec 2008, [Epub ahead of print].

[73] B.M. Everett, S. Bansal, N. Rifai, J.E. Buring and P.M. Ridker, Interleukin-18 and the risk of future cardiovascular disease among initially healthy women, Atherosclerosis 202(1) (Jan 2009), 282-288. 


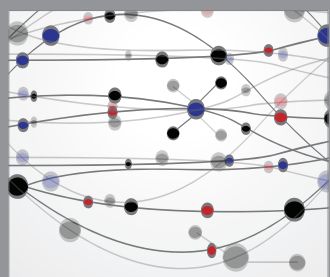

The Scientific World Journal
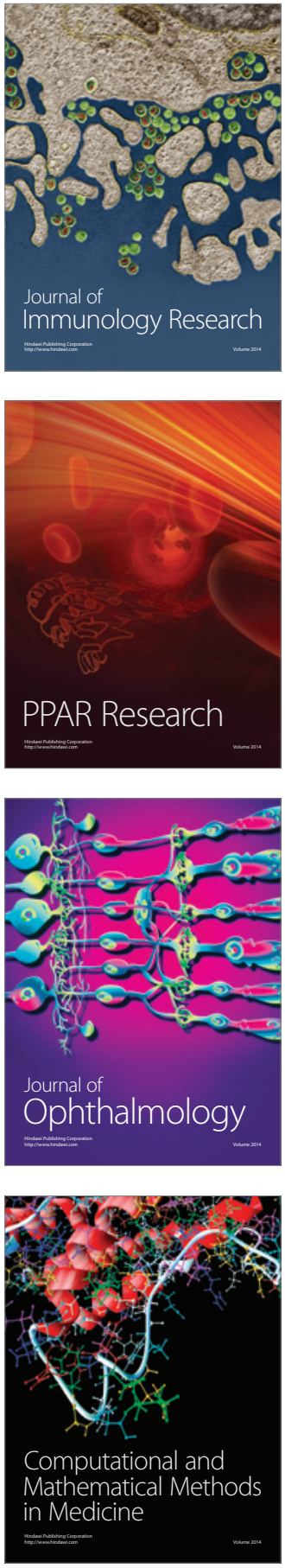

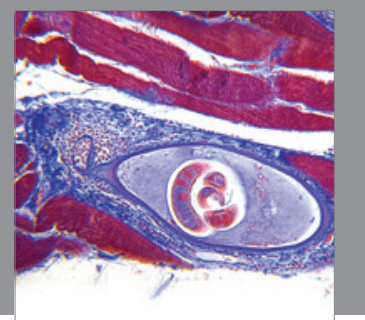

Gastroenterology

Research and Practice
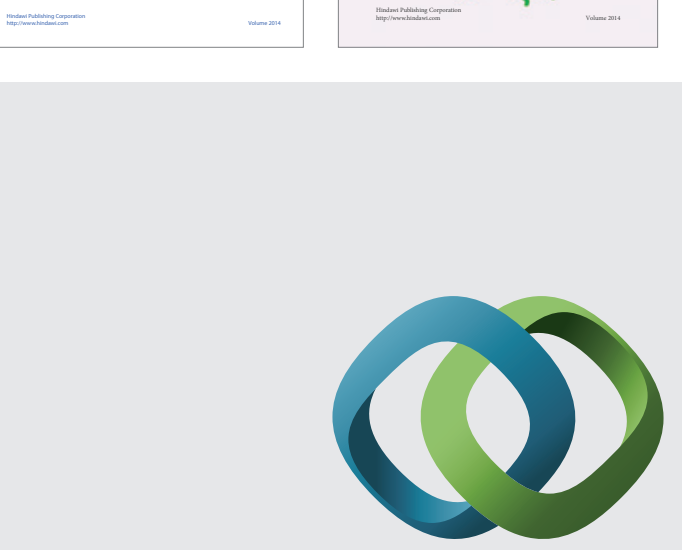

\section{Hindawi}

Submit your manuscripts at

http://www.hindawi.com
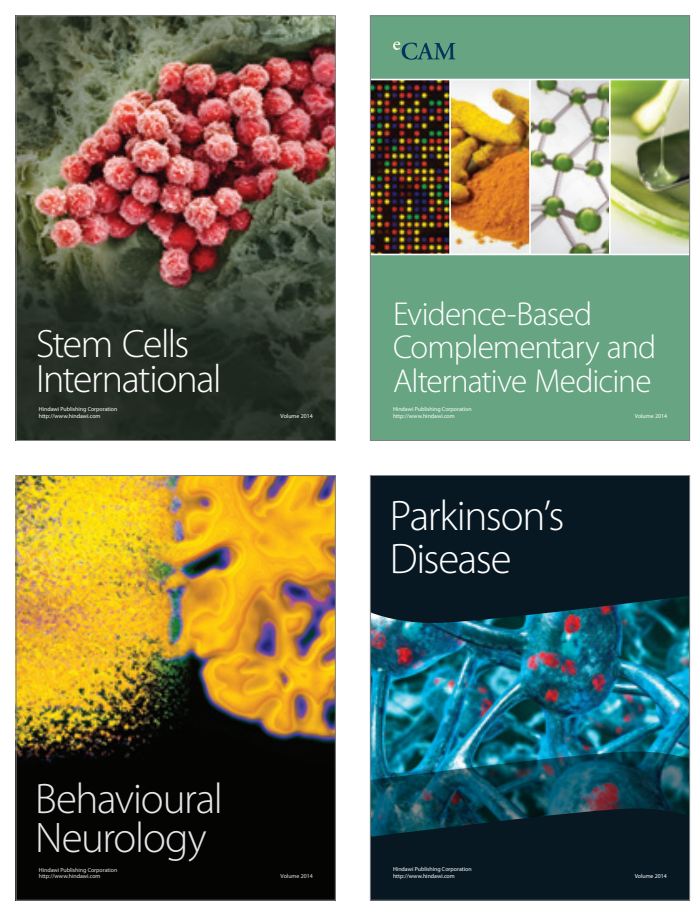

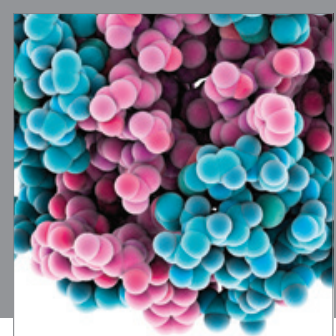

Journal of
Diabetes Research

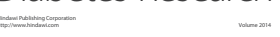

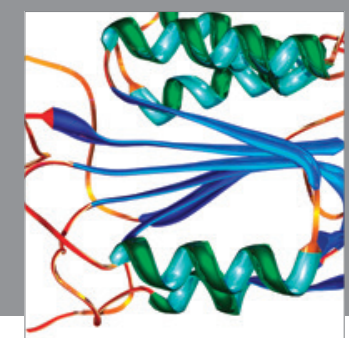

Disease Markers
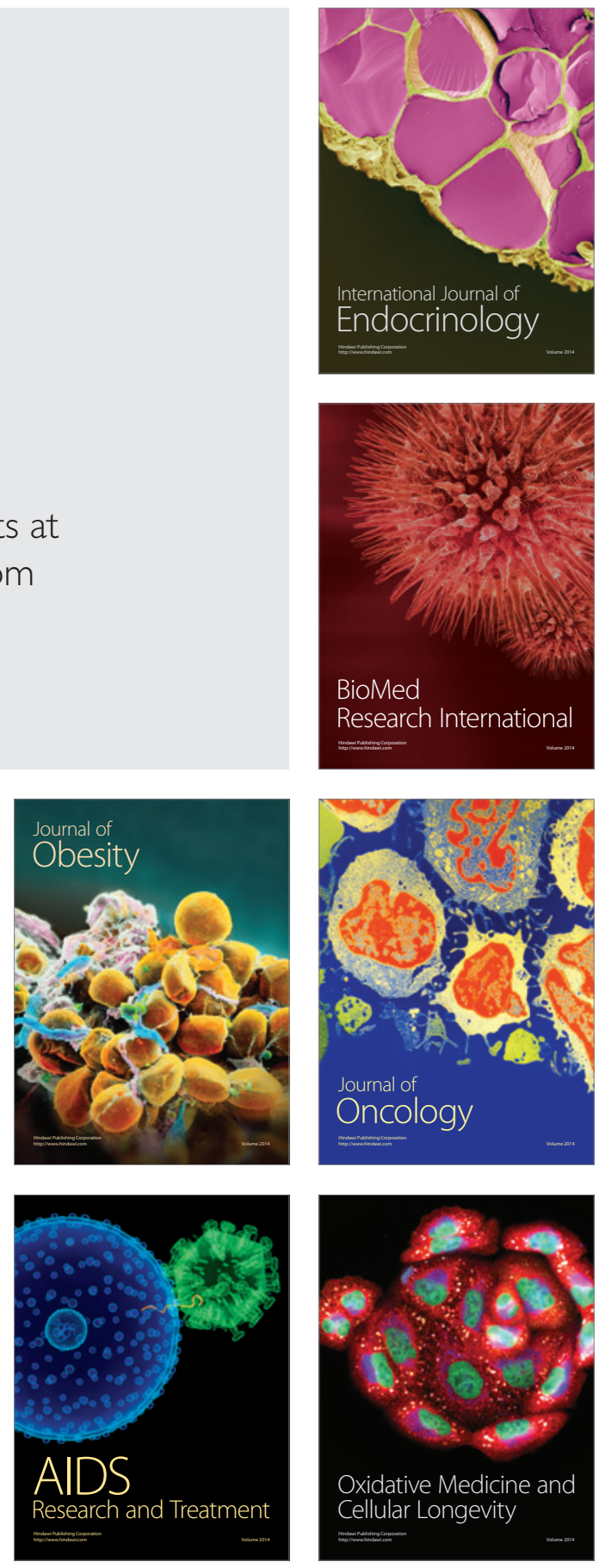